\title{
ZAGZEBSKI, AUTHORITY, AND FAITH
}

\section{TRENT DOUGHERTY}

Baylor University

\section{INTRODUCTION}

Epistemic Authority is a mature work of a leading epistemologist and philosopher of religion (and metaphysician, too, but that character doesn't feature in this story). It is a work primarily in epistemology with applications to religious epistemology. There are obvious applications of the notion of epistemic authority to philosophy of religion. For, on the face of it, the notion of some kind of 'epistemic authority' may serve as a conceptual anchor for our understanding of faith. Indeed, there is ample historical precedent for this. Faith, says Locke, is 'the assent to any proposition ... upon the credit of the proposer, as coming from God, in some extraordinary way of communication.' ${ }^{1}$ In later Lockeans, 'credit' is often rendered 'authority', and the terms were used synonymously at the time of his writing. ${ }^{2}$ One of the beauties of Locke's view is its reductionism, that is, it's parsimony, which is a species of elegance and therefore beauty. Zagzebski's notion is more high-octane than Locke's. In this essay I will do four things. In Section 1 I will describe two kinds or notions of authority or at least two usages of the word 'authority'. In Section 2 I will describe Zagzebski's use of one of these notions, the non-Lockean one, to ground the reasonableness of religious belief. In Section 3 I will give four arguments against her view. In section 4 I will reply to her critique of Locke. The upshot, in my view, is that though we learn much (very much indeed) from Epistemic Authority (about both testimony in general and religious testimony in particular among many other things), a more Lockean approach to the nature of faith is still preferable.

\footnotetext{
${ }^{1}$ Locke, Essay, Book IV, Chapter XVII, section 2.

${ }^{2}$ See, for but two examples, Leland (1740: 15), and Meadly (1809: 16).
} 


\section{TWO KINDS OF AUTHORITY}

\subsection{Expert Authority}

The first kind of authority I shall call expert authority. This usage is usually met in a sentence such as 'She is an authority on horses', or 'He is an authority on the game of golf', or 'She is an authority on $19^{\text {th }}$ Century Russian Novels', or 'He is an authority on first century Palestine'. In each of these sentences, the word 'authority' could be replaced with 'expert' without addition or loss. What we mean when we say such things is (at least) that so and so knows lots about that subject. And we also intend to convey (most of the time) ${ }^{3}$ that that person is a reliable source of information - they are very likely to state the truth of the matter concerning that area - and so their testimony can be relied upon ${ }^{4}$ ( $=$ we can trust them in the matter $=$ believing them is warranted $=$ their says-so is evidence that it is so).

Notice, though, that if $\mathrm{X}$ is an expert it is still an open question whether and in what manner X's opinion, expert though it be, should affect your opinion. For you yourself may be an expert! And of course being an expert on some subject - taking the sentences above as paradigmatic - comes in degrees. So imagine two dials side by side. One dial represents A's expertise on a subject, another represents B's. Let the dials have ten 'clicks' labelled from ' 1 ' to '10'. Here are the possible pairs of settings representing the relationship between A's expertise to B's expertise.

$$
\begin{aligned}
& \{\langle 1,1\rangle,\langle 1,2\rangle,\langle 1,3\rangle,\langle 1,4\rangle,\langle 1,5\rangle,\langle 1,6\rangle,\langle 1,7\rangle,\langle 1,8\rangle,\langle 1,9\rangle,\langle 1,10\rangle \text {, } \\
& \langle 2,1\rangle,\langle 2,2\rangle,\langle 2,3\rangle,\langle 2,4\rangle,\langle 2,5\rangle,\langle 2,6\rangle,\langle 2,7\rangle,\langle 2,8\rangle,\langle 2,9\rangle,\langle 2,10\rangle \text {, } \\
& \langle 3,1\rangle,\langle 3,2\rangle,\langle 3,3\rangle,\langle 3,4\rangle,\langle 3,5\rangle,\langle 3,6\rangle,\langle 3,7\rangle,\langle 3,8\rangle,\langle 3,9\rangle,\langle 3,10\rangle \text {, } \\
& \langle 4,1\rangle,\langle 4,2\rangle,\langle 4,3\rangle,\langle 4,4\rangle,\langle 4,5\rangle,\langle 4,6\rangle,\langle 4,7\rangle,\langle 4,8\rangle,\langle 4,9\rangle,\langle 4,10\rangle \text {, } \\
& \text {... } \\
& \langle 10,1\rangle,\langle 10,2\rangle,\langle 10,3\rangle,\langle 10,4\rangle,\langle 10,5\rangle,\langle 10,6\rangle,\langle 10,7\rangle,\langle 10,8\rangle,\langle 10,9\rangle,\langle 10,10\rangle\}
\end{aligned}
$$

${ }^{3}$ There are certain areas - like nutrition - where the people with the most knowledge tend to change their minds frequently or cannot make up their collective mind at any one time: 'Don't eat eggs! Eggs will kill you!' 'No, eat all the eggs! Eggs will save you!' Between this and matters of great expert agreement, there is a spectrum.

${ }^{4}$ Some people make much ado about the notion of reliance, but I do not. What I mean by reliance here has nothing to do with some kind of right to resent those who get it wrong. Rather, I mean something like if you used that person as a source of information to place bets in the relevant field, you'd come out ahead in the long run. 
This set of ordered pairs describes a 'discrete continuum' (if you will) between two individuals with no expertise (if we let 1 represent the average base unit of knowledge) to two individuals who are each experts. Or we could think of the pairs as representing a continuum of ratios of the expertise of $A$ to $B$ (with a lot of redundant pairs). So the last line would represent $A$ as being very much an expert compared to $B$. Then as we move down the last row, B 'catches up' with A in expertise step by step. So expertise is clearly not a binary notion. And, of course, expertise is not a discrete notion. It is truly continuous so instead of the matrix represented by the set of ordered pairs above, there is an infinite array of possibilities. If we want to try to imagine this array, the best we can do is look at an illustration of the diagonal argument that the rational numbers are countable.

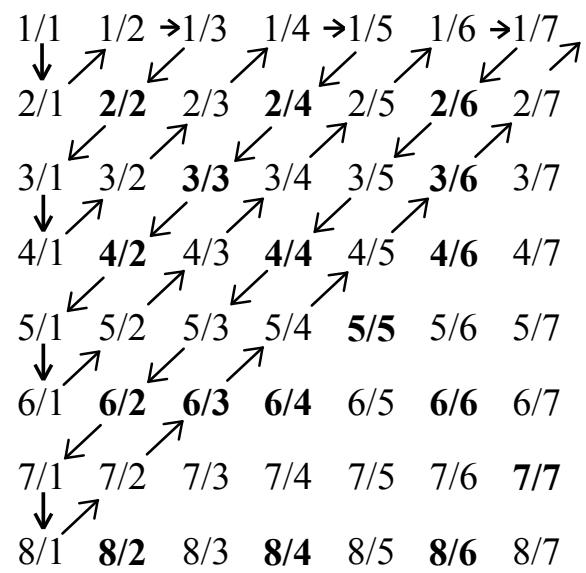

And of course this leaves out infinite infinities of irrational numbers that might express the ratio of A's expertise to B's. The weight of A's testimony might be 6.262 times that of B (or so we may suppose, it doesn't affect the point). I have gone to pains with the visuals in order to illustrate how, well, infinitely short a binary model of expertise would fall from the mark.

Someone who is an authority (to some degree) in this way has authority (to some degree) in this way. And since this kind of authority the kind an expert has (we might as well call it 'expertise') - is based on various good-making features of their beliefs, ${ }^{5}$ we can sensibly call it

${ }^{5}$ It wouldn't have to be knowledge, and often likely isn't. What's really important is that their beliefs be sufficiently likely to be true, on some relevant notion(s) of 'likely'. 
epistemic authority. There is nothing at all mysterious about this kind of epistemic authority. We meet it in the doctor's office, in the classroom, at church, at work, and many other places in daily life.

The Lockean thesis that faith is belief on the basis of the authority ${ }^{6}$ of the proposer, when 'authority' is used to express expert authority (as I believe Locke intended it) is a sensible, familiar idea. It explains why 'walking by faith, not sight' can be reasonable. I've never seen the Great Wall of China. But someone who has been there many times can tell me something about it, say that it is wider in inner Mongolia than it is down in Beijing, and my (reasonably) believing his testimony. That is, we are (epistemically) trusting her (like we would a thermometer). We are having (epistemic) ${ }^{7}$ faith that though we have not seen it with our own eyes, we yet believe that it is so. Note that it is an open question whether this kind of belief counts as knowledge. Sometimes, it seems clear enough, that belief on the basis of expert testimony counts as knowledge. Other times, it will be less clear. But on this notion of faith some of the things we believe by faith we know by faith. The matter of first importance, though, is that belief on the basis of epistemic authority is perfectly reasonable. In non-binary terms, we are warranted in having great confidence in many items we take by faith. We can sensibly assign them high degrees of probability. This is the notion of epistemic authority I find in Locke and find to be true. My position is that this notion of epistemic authority is the best model for 'faith that' in religious belief. Not that on my account trusting an authority that $\mathrm{p}$ is just a species of believing that $\mathrm{p}$. Trusting (epistemically) in some authority is just using them as a source of justification. And someone needs evidence that someone is an expert to reasonably treat them as an authority. This is very much in the spirit of Hume as well. For this reason, and because it is a very unpopular term, I'll call the view I'm advocating here the 'Enlightenment' view. It is important to note here that I do not accept the standard narrative according to which Locke and Hume removed all communal notions from their epistemology, which Zagzebski seems to place a lot of stock in (p. 112). However, I am very glad we share this common ground: 'I think Locke is right that faith is tied to belief on

\footnotetext{
${ }^{6}$ Really it is upon the perceived authority, but that is merely a wrinkle.

${ }^{7}$ Epistemic faith I take to be a species of ordinary belief. I affirm the tradition of distinguishing between 'faith that' (what I have called 'epistemic faith') and 'faith in' which is a kind of interpersonal trust of individuals. 'Saving faith' or 'trusting in God/ Christ' is a species of 'faith in'. I am not treating 'faith in' in this essay.
} 
testimony, and the rationality of faith is therefore tied to the rationality of belief on testimony.' (p. 112)

The obvious sense of the Enlightenment view makes it hard to understand Zagzebski's final words in her chapter about religious epistemic authority: 'Religious faith is impossible to explain, much less justify, on the evidence view of testimony. That view forces us to either redefine faith as belief on a certain kind of evidence, as Locke did, or we must say that faith is nonrational.' (p. 179) That faith (that) is a kind of belief on a kind of evidence is run of the mill, as the examples above show. So there is no need for any redefinition. Things are fine just as they are. And the following is also unfair to Locke:

Taking a belief from Scripture or from a religious tradition would not be justified at all according to the extreme egoist. That is to say, the belief would not be justified because it is from Scripture or tradition. If the belief is justified, it is because it is justified by the use of my faculties anyway. The fact that the same belief is included in Scripture or the tradition is irrelevant. (p. 167)

What's true is that it would not be justified just because it is from Scripture or tradition, for there are many scriptures and many traditions, and one must have some reason - independent of the mere fact that it is Scripture $\mathrm{G}$ or Tradition $\mathrm{T}$ - to believe $\mathrm{G}$ or $\mathrm{T}$ on the matter rather than $\mathrm{X}$ or $\mathrm{Y}$. But from this it does not follow that it is irrelevant that it is included in Scripture or tradition for the simple reason that had Scripture or tradition not included it I never would have known it (or not as easily or as clearly), since my faculties are by themselves insufficient to attain to many of the truths revealed in Scripture and tradition. Also, it's because Scripture and tradition bear a certain relation to God Himself that they are worthy of belief. So on any reasonable view at all one does not believe something just because it is from Scripture or tradition. Below, I will defend Locke's view on authority and choice.

\subsection{Juridical Authority}

The other kind of authority I will call juridical authority. This is the authority you might think a Sergeant in the Army has over a Private, a CEO has over an office manager, that deans seem to think they have over professors, and that Police would have over Citizens if a government were just. I'm dubious of the notion of juridical authority as such. I'm inclined to think that as moral agents no one can have authority over 
us - including God - unless we grant it to them. But I don't need to defend that here.

'What is essential to authority', says Zagzebski, 'is that it is a normative power that generates reasons for others to do or to believe something preemptively' (p. 89). The key term is 'preemptively'. She notes the presence of pre-emption in Joseph Raz's notion of juridical authority. ' $\mathrm{T}]$ he fact that an authority requires performance of an action is a reason for its performance that replaces other relevant reasons and is not simply added to them' (p. 93, emphasis added). Then she presents her epistemic analogue:

\section{Preemption Thesis for epistemic authority}

The fact that the authority has a belief $\mathrm{p}$ is a reason for me to believe $\mathrm{p}$ that replaces my other reasons relevant to believing $\mathrm{p}$ and is not simply added to them.

She observes that this principle might be thought to be impossible: We must ignore our own reasons. But she says we do not ignore our reasons when we pre-empt them. 'In fact, it is because I am not ignoring them that I see that the belief of the authority has a certain status vis-à-vis my other reasons.' (p. 98) It is all well and good to say this, but what is utterly mysterious is how we can focus on our reasons (the opposite of ignoring them) and yet they have no motive force (apart from malfunction). How can we look a reason 'square in the face' and remain (non-degenerately) unmoved? There are deviant cases, of course, but this is supposed to happen systematically and virtuously. She relies on a dubious difference between first-person reasons and third-person reasons, saying that they do not aggregate (pp. 56-58 ). But why not? Why can't reasons of different kinds aggregate? They seem to in ordinary cases of testimony (where we don't have to think of the testifier as an authority). I see grocery bags on the floor and conclude that Jim when to the market. Jill tells me he did. I rightly believe more firmly when Jill's testimony is added to my experience. Very different kinds of reasons aggregate. Furthermore, her distinction rests on the distinction between first- and third-person reasons, but I reject the notion that there are any third-person reasons but rather that all reasons are first-personal (see Dougherty and Rysiew 2009, Conee and Feldman 2004, Heumer 2001, Swinburne 2001). It is this dubious alleged difference between first- and third-person reasons which supports her reasoning in her chapter on religious faith that the evidence theory of testimony is false (p. 168). A word about that is in order. 
Zagzebski adopts the common sentiment that there is more to testimony than evidence. 'As Moran (2005) has pointed out, there is no explanation for feeling let down when the testimony is false if testimony is evidence.' (p. 108) Of course there is more to testimony than evidence. It's a human practice, so there is bound to be a social normative dimension. The question is whether this 'more' plays any role in the justification of beliefs obtained from testimony. And the social stuff itself is part of what makes testimony evidence-generating. I can tell, instinctively, when someone is representing themselves as having a certain degree of warrant for a proposition, p, expressed by an utterance they make. I am attending, often unconsciously, to features of the social situation which themselves are of evidential significance. Grice's rules of interpretation are psycho-social in nature, and the textbook Gricean interlocutor uses social norms as premises in an argument for the conclusion that $\mathrm{S}$ has certain information relative to $\mathrm{p}$.

Zagzebski says (p. 118) the 'egoist' or proponent of the Enlightenment view should or can accept her main theses regarding testimony. (p. 116)

Justification Thesis 1 for the Authority of Testimony (JAT 1)

The authority of a person's testimony for me is justified by my conscientious judgment that I am more likely to satisfy my desire to get true beliefs and avoid false beliefs if I believe what the authority tells me than if I try to figure out what to believe myself.

Justification Thesis 2 for the Authority of Testimony (JAT 2)

The authority of another person's testimony for me is justified by my conscientious judgment that if I believe what the authority tells me, the result will survive my conscientious self-reflection better than if I try to figure out what to believe myself.

When I first read these principles I was perplexed as to how they depended on any of the prior material. So I was a bit relieved when she said that Lockeans could accept them or modified versions of them. However, I can't quite tell if this is correct, because she says this:

Suppose I hear speaker S say that $\mathrm{p}$ and reasonably take that to be either direct or inductive evidence that $\mathrm{p}$. I then believe $\mathrm{p}$ on S's testimony. If I also have evidence that $S$ is more likely to get the truth whether $p$ than I am, then I ought to believe p on her testimony, and I ought to believe preemptively. (p. 118) 
Because of the weighting model I presented above, I just don't think there is any need at all for preemption. That is, I see no reason at all to just set aside my own reasoning per se. There are only two scenarios where I can see this as reasonable. First, there is the case where I have thought it through but gain evidence sufficient to make certain that I have absolutely no idea what I'm doing. In this case, I should abandon any hope in my reasoning and give it no weight. But if I am less than certain that there is no hope, then I ought to give my reasoning some weight (and, as is clear, the maths allows me to give it arbitrarily low weight). The other scenario isn't technically of the same kind, that is it is not a case of setting aside reasoning at all, but it is the analogue in the realm of action. This is the scenario where I am considering whether to investigate a matter and think it through. Before I am to begin I learn that you are in so much better an epistemic position than me that it would be a waste of my time and resources to even bother about it. The odds of my investigation and reasoning affecting my outcome credence by a significant margin are so low that thinking about it myself has negative expected utility. In this case I 'set aside' my attempt to think through the matter myself. This can make perfect sense because I haven't yet gone to the effort and therefore have no reasons to 'set aside'. Outside of these two cases - the one merely theoretical, since I don't think one should ever assign 1 or 0 to any proposition - and the other in the realm of action - I cannot think of any reason to ever utterly discount our own reasoning. Unlike the former case, the latter may be quite widespread, and I hypothesize that this kind of phenomenon is what is driving the bus, and it is just a confusion to think of it as relating to epistemic reasons. The reasons in this case are practical reasons.

There is much left out of this characterization which is important, especially Zagzebski's notion of the communal in religious authority. However, that material is built upon the distinction between theoretical and deliberative reasons and, especially, on the notion of epistemic authority as pre-emptive, wherein one sets aside one's own reasoning. My arguments below will be aimed primarily at the pre-emptiveness of juridical epistemic authority.

\subsection{THE ARGUMENT FROM PARSIMONY}

My first argument in favour of the Enlightenment view over the Juridical or Pre-emption view is an argument from parsimony. 
Parsimony argument

(1) The notion of expert epistemic authority is completely nonmysterious and one both sides are committed to.

(2) Expert authority is sufficient to explain the relevant epistemic practices (esp. the reasonableness of accepting testimony).

(3) If 1 and 2, then unless there is compelling reason to posit a new, mysterious notion of epistemic authority, one should not do so.

(4) There is no compelling reason to posit a new, mysterious notion of epistemic authority.

Therefore,

(5) There we should not posit a new, mysterious notion of epistemic authority.

Premise 1 seems secure. Premise 3 is an expression of the Principle of Parsimony: don't posit new things without due cause. Partial defence of 2 and 4 come from remarks above.

\subsection{The argument from the aim of belief}

The second argument begins from the familiar notion that belief, in some sense or other, 'aims' at truth. I actually think belief aims at empirical adequacy (Dougherty 2014), but I suspect that Zagzebski and many others hold some kind of view that will do the trick.

B1 Belief aims at truth.

B2 If belief aims at truth, then if a mental state doesn't aim at truth, that state isn't one of belief. [B1]

B3 If a mental state doesn't aim at truth, that state isn't one of belief. [B1, B2 MP]

B4 Any state that is formed (wholly) in response to considerations other than signs of truth (i.e. evidence, broadly construed) is not aimed at truth.

B5 Any state that is formed (wholly) in response to considerations other than evidence, isn't one of belief. [B3, B4 HS]

B6 The state of assent formed in response to authority is not a response to evidential considerations (else it wouldn't really be epistemic authority).

B7 The state of assent formed in response to authority is not a state of belief. [B5, B6 HS] 
All of the basic premises of this argument seem true by definition to me, so I'm unsure what to even try to defend (or how I would do it).

\subsection{Degrees of Authority}

Epistemic authority, as Zagzebski conceives it, is binary in a certain way. It appears that you should set aside your own reasoning when you rely on an epistemic authority in her sense. It is not, as it would be with expert authority in my sense, combined and weighed with your own judgment. She says, 'a small difference between myself and the putative authority is not likely to be sufficient to ground authority' (p. 96). The idea seems to be that there needs to be a large difference between one and a putative authority before one pre-empts one's own reasoning. Presumably, prior to crossing this critical threshold one continues to rely on one's own reasoning. But this seems strange. It ignores the difference between small differences in expertise and not-so-small differences in expertise. ${ }^{8}$

On the generalization of testimonial evidence I have provided (Dougherty 2013), weighing one's own reasoning against the epistemic authority is as easy as calculating a student's final grade. Say Maria is an expert with respect to some class $\mathrm{K}$ of propositions to which $\mathrm{p}$ belongs (and is the only relevant category in this case), and she is .8 confident that $\mathrm{p}$. It seems to me, let us suppose, that she is being too cautious. My own judgment is that on the evidence available to Maria and me, one should rate $\mathrm{p}$ at .9. However, I recognize that Maria is an expert to the following degree: her opinion should count twice as much as mine. My final credence in $\mathrm{p}$ then is figured thusly: $(.8+.8+.9) / 3=.833$. The method is the same even if there is only 'a small difference' between Maria and me. If her opinion should count for $110 \%$ of mine ${ }^{9}$ we have $(.9+1.1(.8)) / 2.1=.848$. As expected, this is just slightly below the straight (unweighted) average of our credences, .85 . This is a fully general

${ }^{8}$ There is also the problem of the vagueness itself, which I don't have space to go into in any detail here. The problem is that there will be no bright line such that from exactly that line on we pre-empt our own reasoning and below it we don't. But we must either pre-empt or not pre-empt. So there seems to be a necessary mismatch between reality and practice on the pre-emption model.

${ }^{9}$ This is actually consonant with Zagzebski's 'Principle of Epistemic Trust in Others' (p. 186), and she does talk about degrees of trust (p. 188), but then she goes back to binary language when talking about resolution of disagreement: 'Given the argument of this book, it is reasonable to resolve the conflict in favor of what I trust the most when I am thinking in the way I trust the most' (p. 189) and that resolving disagreements means we need to 'target the belief that should be given up' (p. 191). 
account of how to weigh authority. Furthermore, this method can handle multiple competing authorities of various weights. It is just like figuring a slightly more complex grade with more quizzes, a midterm and a final, all of different weights. And this is a very good result, since epistemic authority clearly comes in degrees. It is hard to see how Zagzebski's account can handle degrees of epistemic authority in such an elegant way or even at all. 'Why isn't it more reasonable', she asks, 'to add my other reasons to the balance of reasons, perhaps weighing the authority's belief more heavily than my other reasons? Isn't the authority's belief just one more piece of evidence that I put into the mix of my total evidence?' (p. 99) She favours pre-emption over weighing. This seems like exactly the wrong result in light of the existence of degrees of authority.

\section{REJOINDER TO ZAGZEBSKI ON BEHALF OF LOCKE}

Zagzebski considers Locke's objection to a duty to believe in obedience to authority stemming from the fact that belief does not depend upon the will. In objection, she offers essentially this argument.

N1 Beliefs have norms.

N2 If beliefs have norms, then we can exercise control over them.

Therefore,

N3 We can exercise control over beliefs.

In defence of $\mathrm{N} 1$ she says that we teach norms to students (p. 87). It's not clear what norms she is referring to. Here is the sort of norm you might think she has in mind (to a student who is writing a research paper, say): Base your thesis on adequate research. But this comes to little more than the conjunctive injunction Do research and have it in mind when writing. But this isn't a norm of belief at all. This is a norm of writing. We might get more specific with When you write down your thesis, think about what evidence there is for it amidst your research. That is at least an instruction to think about something. Though this is not an injunction to form a belief, it can be expected to result in beliefs for a properly functioning person. So I'm going to ask you right now to think about when your birthday is. The odds are, being an agreeable sort of reader, you complied. And odds are if you did think about it you spontaneously formed the belief that your birthday was on such and such a day. The formation of the belief itself was spontaneous, it was not up to you to do or not to do. There 
is likely nothing you could do to resist it. So the belief was unfree, not something you were responsible for. Yet it was something over which you had some kind of positive control. For any given number within a certain limit, you can quickly comply with a request to form the belief that it is not prime. You do this not by taking direct aim at the formation of a belief but rather by directly bringing it about that you are thinking about either some evidence for some target proposition or by simply thinking of the content of some self-evident proposition.

The above fits will the term 'reflective self-control', which Zagzebski sometimes uses to describe the kind of control she thinks we have over belief. But it is hard to see what application this could have for the idea of epistemic authority in the juridical sense (vs. the expert sense). For if the belief is formed in virtue of one's responsiveness to ordinary reasons, then there is no role played by juridical authority. So even if one was being obedient to juridical authority in engaging in the act of reflection, that isn't the salient explanation of the formation of the belief. At least the dominant explanation is evidential. Someone, in an attempt to get me to believe Goldbach's conjecture, might order me to go into a room. Once in the room I see Goldbach's conjecture written on the wall quite large and come to believe it. We would hardly highlight the juridical authority of the one who sent me to my room as the dominant epistemic explanation of my belief in Goldbach's conjecture. The juridical authority merely occasioned it. So though there is a certain kind of guidance control over belief, it is not of the sort to provide a model for pre-empting reasons.

\section{CONCLUSION}

My position is that God's authority is the authority of the expert, like the expert on horses, who has no jurisdiction at all, whereas one who does have jurisdiction may lack authority due to ignorance (the latter claim is not strictly necessary for my argument). There is not much the Pope can actually do to me, but has 'moral authority' because he is a reliable source of information about what to do in life generally. (And I have also made a vow of obedience to the Church when I was confirmed as a Catholic, but I freely made that vow, so the juridical authority it gives rise to is not a problem for my view.) We are wrong to model God's authority (or the Church's authority, which ultimately derives from God's authority) on that of juridical authority. The reason to obey God in general is not that he is the 'Big Boss' with so much power, 
but rather because as a loving God he wants what is best for us and as an omniscient God he always knows what that is. And so it is, Lockeans say, with belief. We should believe what God says or the Church says not because of a position they have over us but rather because we have good reason to believe that God and the Church want the best for us and God always and the Church usually knows what that is (the Church within its defined sphere). ${ }^{10}$

\section{BIBLIOGRAPHY}

Conee, Earl \& Feldman, Richard. 2004. Evidentialism (Oxford: Oxford University Press)

Dougherty, Trent. 2014. 'The Ethics of Belief is Ethics (Period)', in Tim O'Connor and Lara Goins (eds), Faith and Epistemic Virtue (Oxford: Oxford University Press)

Dougherty, Trent. 2013. 'Dealing with Disagreement from the First Person Perspective: A Probabilist Proposal', in Diego Machuca (ed.), Disagreement and Skepticism, Routledge Studies in Contemporary Philosophy, vol. 46 (New York: Routledge)

Dougherty, Trent \& Rysiew, Patrick. 2009. 'Fallibilism, Epistemic Possibility, and Concessive Knowledge Attributions', Philosophy and Phenomenological Research, 78 (1): 123-132

Feldman, Richard. 2004. 'Having Evidence', in Conee and Feldman (2004).

Huemer, Michael. 2001. Skepticism and the Veil of Perception (Lanham: Rowman \& Littlefield)

Leland, John. 1740. Answer to a Book Entitled 'Christianity as Old as the Creation' 2nd ed. (London: Richard Hett)

Meadley, G. W. 1809. Memoirs of William Paley, DD (London: J. Graham)

Swinburne, Richard. 2001. Epistemic Justification (Oxford: Oxford University Press)

10 This essay was made possible through the support of a grant from the Templeton Religion Trust. The opinions expressed in this publication are those of the author and do not necessarily reflect the views of the Templeton Religion Trust. 